\title{
Therapeutic Strategies by Regulating Interleukin Family to Suppress Inflammation in Hypertrophic Scar and Keloid
}

\author{
Dan Zhang, Bo Li and Muxin Zhao* \\ Department of Plastic and Cosmetic Surgery, The Second Hospital of Dalian Medical University, Dalian, China
}

Hypertrophic scar (HS) and keloid are fibroproliferative disorders (FPDs) of the skin due to aberrant wound healing, which cause disfigured appearance, discomfort, dysfunction, psychological stress, and patient frustration. The unclear pathogenesis behind HS and keloid is partially responsible for the clinical treatment stagnancy. However, there are now

OPEN ACCESS

Edited by:

Sung Hwan Ki,

Chosun University, South Korea

Reviewed by:

Di Wu,

Chinese Academy of Medical Sciences and Peking Union Medical

College, China

Jia Tian,

Chinese Academy of Medical Sciences and Peking Union Medical

College, China

Kaiyu Nie,

Zunyi Medical University, China

*Correspondence:

Muxin Zhao

zhaomuxin@126.com

Specialty section:

This article was submitted to Inflammation Pharmacology, a section of the journal

Frontiers in Pharmacology

Received: 14 February 2021

Accepted: 05 March 2021

Published: 20 April 2021

Citation:

Zhang D, Li B and Zhao M (2021) Therapeutic Strategies by Regulating

Interleukin Family to Suppress

Inflammation in Hypertrophic Scar

and Keloid.

Front. Pharmacol. 12:667763.

doi: $10.3389 /$ fphar.2021.667763 increasing evidences suggesting that inflammation is the initiator of $\mathrm{HS}$ and keloid formation. Interleukins are known to participate in inflammatory and immune responses, and play a critical role in wound healing and scar formation. In this review, we summarize the function of related interleukins, and focus on their potentials as the therapeutic target for the treatment of HS and keloid.

Keywords: keloid, hypertrophic scar, interleukin, inflammation, therapy

\section{INTRODUCTION}

Hypertrophic scar (HS) and keloid are a kind of FDPs, which mainly manifested by fibroblast proliferation and excessive deposition of extracellular matrix (ECM) (Jiang and Rinkevich, 2020). HS is mostly caused by surgery and severe burns, while keloid may result from minor skin damage, such as ear holes, vaccination, acne, etc (Lee and Jang, 2018). Chronic infections and repeated injuries may enhance scar formation and tissue fibrosis (Vinaik et al., 2020). In morphology, they both exhibit hyperplasia, bulge and redness, but unrestrained growth is a specific feature in keloid, which usually invades beyond the margins of the original wound. A majority of patients have to suffer obvious itchiness and pain for a long time (S. S. Lee et al., 2004). Sometimes it not only affects esthetics but also produces dysfunction. At present, there is still lack of efficient curative treatments. Conventional surgery, radiotherapy and hormonal therapy are difficult to achieve complete cure, especially in keloid due to high recurrence rates (Arno et al., 2014).

Although studies on scars are numerous, the specific pathogenesis mechanism remains unclear in HS and keloid. However, accumulating evidences exist on close link among the inflammation, immune, and pathological scar (Xue et al., 2000; G. Zhu et al., 2007). In the past, keloid and HS were divided into distinct diseases because of the differences in clinical manifestations and pathology (Arno et al., 2014). However, recently, some studies indicate that the difference between them iwas only result of the different duration and intensity of inflammation. Keloid could be defined as pathological scar with severe inflammation, and HS defined as scar with weakly inflammation (Berman et al., 2017). Thus, inflammation as an initial factor will trigger the subsequent immune response cascade, which leads to scar formation. After cutaneous injury, inflammation responses first occur at the site of injury. During the early phase, neutrophil infiltration is the main feature, and the late stage is characterized by monocytes composed of macrophages and lymphocytes (Shimizu et al., 


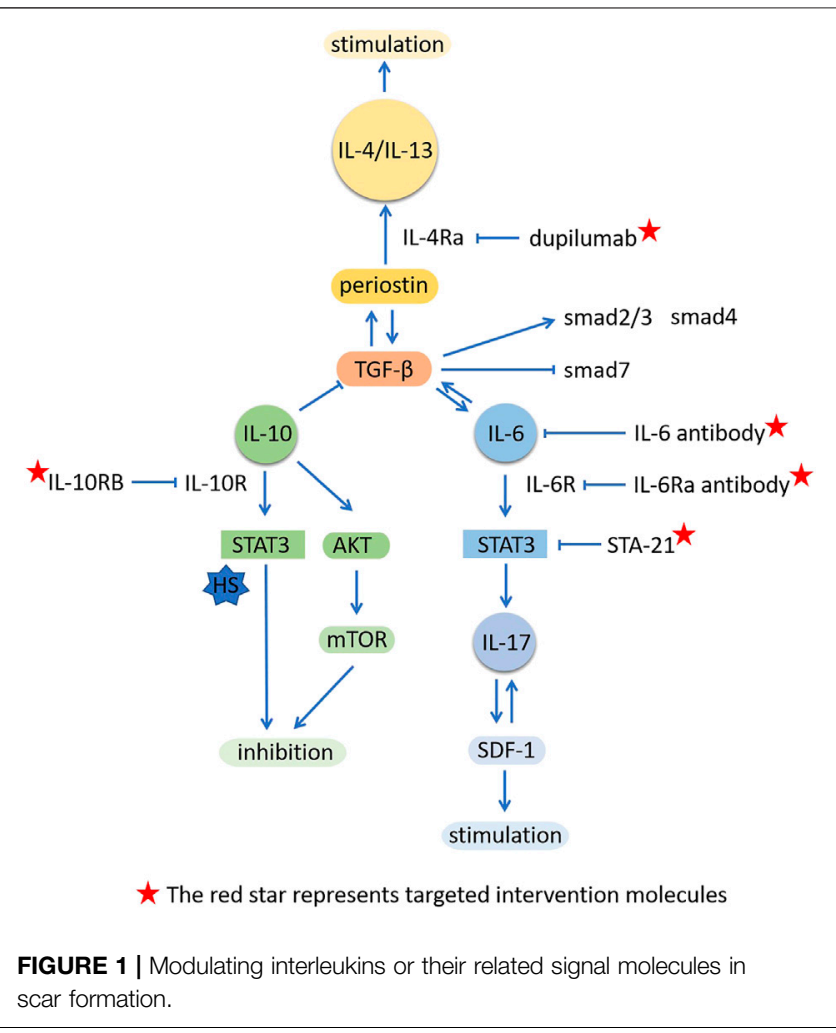

2006). These cells secrete a large number of inflammatory factors such as interleukins, interferons and growth factors, among which interleukins play a prominent role in the initiation of inflammation and subsequent proliferation and remodeling (Abdou et al., 2014). Interleukins act as a major inflammatory factor, potentially regulating fibroblasts recruitment, proliferaton, differentiation, apoptosis and production of ECM. We have observed that the expression of interleukins in scar is different from that of in normal skin (NS). By regulating of interleukin and its related pathways, the phenotype of fibroblasts enhanced or weakened, which suggested that interleukin may serve a significant role in scar. Taken together, we summarize the specific types and changes of interleukins in HS and keloid, and generalize the possible role of regulating the expression and/or secretion of a certain interleukin for abnormal scar prevention.

\section{IL-6}

Interleukin-6 (IL-6) is a proinflammatory factor and a potent immunomodulatory agent (Quong et al., 2017). IL-6 played an important role in chemotaxis and inflammatory cell activation, which was expressed immediately after cutaneous injury and substained over a period of time (Murao et al., 2014). IL-6 could trigger the transition from acute inflammation to chronic inflammation by enhancing monocyte recruitment (Kaplanski et al., 2003). A number of studies had shown that the single nucleotide polymorphism of IL-6 gene affected serum levels.
IL-6-572 GG genotype was associated with increasing the risk of keloid in Egyptian (Abdu Allah et al., 2019), Southeastern Chinese (X. J. Zhu et al., 2017) and Japanese (Tosa et al., 2016). Both IL-6 and IL-8 decreased significantly in early fetal fibroblasts (Namazi et al., 2011), which may help to produce scarless healing. IL- 6 secretion was higher in HS and keloid, and the mRNA and protein levels of IL-6R $\alpha$ and IL-6R $\beta$ (gp130) and its downstream targets LAK1, STAT3, RAF1 and ELK1 were up regulated (Ghazizadeh et al., 2007).

\section{Direct Effect of Targeting IL-6}

IL-6 may be an effective target in treating HS and keloid. When IL-6 peptide was added into human normal fibroblasts (NFs), the expression and synthesis of collagen were revealed a dosedependent increase (Ghazizadeh et al., 2007). If monoclonal anti-IL-6 or anti-IL6Ra antibody were added, the progress would be prevented. Ray et al. (Ray et al., 2013) also demonstrated that IL- 6 increased the production of ECM and cellular proliferation mediated by STAT3 pathway in HS. Counter regulating the overexpression of IL- 6 may be a key trigger factor to inhibit the prolongation of inflammatory phase in keloid wound healing (Euler et al., 2019).

\section{Regulation of IL-6 Expression and/or Secretion}

In addition, modulating the IL- 6 signaling pathway may also affect the wound healing and scar formation (Figure 1). Currently, several treatments for HS and keloid are known to regulating the expression and/or secretion of IL-6 (Table 1). We here summarized these treatments as follows.

\section{Synthetic Drugs}

Initial results with angiotensin receptor blocker (ARB) and angiotensin converting enzyme inhibitor (ACEI) in the treatment of keloid and HS were encouraging (Kilmister et al., 2019). Renin angiotensin aldosterone system (RAS) components which are expressed in various cells of skin and act independently of plasma RAS, play an important role in wound healing and scar formation. By acting on AT1 receptor (Mulrow. 1999), angiotensin II promoted fibrosis, induced migration and proliferation of keratinocytes and fibroblasts, and increased collagen production through IL-6/TGF- $\beta$ and AP-1/TGF- $\beta$ pathways (Hedayatyanfard et al., 2020). The activation of AT2 receptor inhibited the above-mentioned process by blocking the expression of IL- 6 , TNF- $\alpha$ and TGF- $\beta$, and played an antiinflammatory role (Hedayatyanfard et al., 2020). Triamcinolone acetonide (TA) has been routinely used as a treatment for keloid. It was a corticosteroid hormone that could reduce the expression of IL-6 and vascular endothelial growth factor (VEGF) (Johnson et al., 2020). Botulinum toxin A (BTA) is effective on keloid and HS (R. Hao et al., 2018). In the keloid model of athymus mice, BTA reduced inflammatory infiltration and collagen tissue, comparing with the gold standard triamcinolone acetonide, and the former showed less side effects (Fanous et al., 2019). Chen (L. Chen et al., 2019) showed that BTA could reduce the proliferation and migration of 
TABLE 1 | Treatments regulating IL-6 in HS and keloid.

\begin{tabular}{|c|c|c|c|c|}
\hline Treatment & Disease & Pathway & Effect & References \\
\hline ARB/ACEI & HS/keloid & IL-6/TGF- $\beta$ and AP-1/TGF- $\beta$ & IL-6,TNF- $\alpha$ and TGF- $\beta \downarrow$ & Hedayatyanfard et al. (2020) \\
\hline TA & HS/keloid & & IL-6 and VEGF $\downarrow$ & Johnson et al. (2020) \\
\hline BTA & HS/keloid & JNK & TGF- $\beta$, IL-6, CTGF and side effects $\downarrow$ & L. Chen et al. (2019) \\
\hline Verapamil & HS/keloid & & IL-6 and VEGF $\downarrow$ & Foubert et al. (2017), Giugliano et al. (2003) \\
\hline Pirfenidone & HS & & IL-6, IL-2 and neutrophil infiltration $\downarrow$ & Medina et al. (2019) \\
\hline Sulforaphane & keloid & STAT3/Smad3 & $\mid L-6 \downarrow$ & Kawarazaki et al. (2017) \\
\hline PTXL & keloid & Akt/GSK3 $\beta$ & TNF- $\alpha, I L-6$ and TGF- $\beta \downarrow$ & M. Wang M. et al. (2019) \\
\hline Emodin & HS & PI3K/Akt & 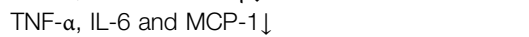 & C. Liu (2015) \\
\hline Curcumin & HS/keloid & & IL-1, IL-6 and IL-8\ & Jia et al. (2014) \\
\hline Naringin & HS & & TNF- $\alpha,\|L-1 \beta\| L-$,6 and TGF- $\beta 1 \downarrow$ & Shan et al. (2017) \\
\hline Ginseng & HS & & $N F-\kappa B, T G F-\beta 1, \mid L-6 \downarrow$ & Pazyar et al. (2012) \\
\hline Ginsenoside Rg3 & HS & $N F-\kappa B / / \kappa B$ & $\|\mathrm{~L}-1 \beta,\| \mathrm{L}-6$, and TNF- $\alpha \downarrow$ & Ma et al. (2020) \\
\hline GNA & HS & & TGF- $\beta 1$, CTGF, IL-1 $\beta, \| L-6$, TNF- $\alpha \downarrow I L-10 \uparrow$ & Jun et al. (2021) \\
\hline Lapadan & HS & & IL-6 and PAI- $1 \downarrow$ & Matsui et al. (2011) \\
\hline Stem cells & HS/keloid & & 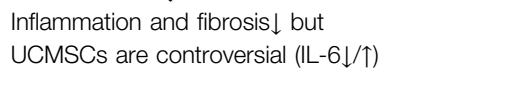 & $\begin{array}{l}\text { Fong et al. (2014), J. Liu et al. (2018), } \\
\text { Fang et al. (2016), Jiao et al. } \\
\text { (2017), Arno et al. (2014a) }\end{array}$ \\
\hline НВОТ & keloid & & Inflammatory factor $\downarrow$ (IL-6\/-) & Song et al. (2018), Y. Hao et al. (2020) \\
\hline $\mathrm{IFN}-\gamma$ & keloid & JAK/STAT3 and Jak1/STAT1 & IL-6 and col1 synthesis $\downarrow$ & Euler et al. (2019) \\
\hline TSG-6 & HS/keloid & & $\|\mathrm{L}-1 \beta,\| \mathrm{L}-6$ and $\mathrm{TNF}-\alpha \downarrow$ & H. Wang H. et al. (2015) \\
\hline SVF-gel/cells & HS & & IL-6 and MCP- $1 \downarrow$ & J. Wang J. et al. (2019) \\
\hline PLM & HS & & IL-6 and TNF- $\alpha$ level in both serum and tissuse $\downarrow$ & Demircan et al. (2021) \\
\hline UVA & keloid & $\mathrm{p} 38 / \mathrm{NF}-\kappa \mathrm{B} 1$ & 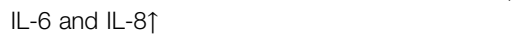 & Niu et al. (2020) \\
\hline
\end{tabular}

fibroblasts through JNK pathway activation, and inhibit the protein expression levels of TGF- $\beta$, IL- 6 and connective tissue growth factor (CTGF). In contrast, in a culture with dermal fibroblasts and microvascular endothelial cells, the above phenomenon was not observed (Haubner et al., 2012). Verapamil is also a controversial drug for scars. It was a calcium channel blocker (W. Wang et al., 2016), which could inhibit the growth of central keloid fibroblasts (KFs), induce apoptosis, reduce the production of IL- 6 and VEGF and the synthesis of ECM (Giugliano et al., 2003; Foubert et al., 2017). This treatment was considered safe (Verhiel et al., 2015), but there was still no consensus on the therapeutic value (Danielsen et al., 2016; Abedini et al., 2018). Due to some methodological defects, it needs larger samples and better models to verify. Pirfenidone, as an FDA approved antifibrotic drug, regulated wound inflammation by reducing the expression of inflammatory factors such as IL-6, IL-2 and neutrophil infiltration in deep burn model of mice, which reduced the formation of scar (Medina et al., 2019).

\section{Natural Extraction Medicine}

In addition to conventional drugs, some ingredients from natural plants also play a role in the treatment of $\mathrm{HS}$ and keloid. Sulforaphane, an isothiocyanate extracted from cruciferous vegetables (such as broccoli sprouts), down-regulated the expression of IL- 6 in KFs by inhibiting NF- $\kappa \mathrm{B}$, and also inhibited STAT3 and smad3 signal transduction pathways (Kawarazaki et al., 2017). Paclitaxel (PTX) was an effective chemotherapeutic drug, which has been reported to have antifibrosis effect (C. Wang et al., 2013). Its modified form (PTXL) could inhibit the growth and invasion of keloid, and showed better effect. At the same time, PTXL also reduced the production of fibrosis cytokines including TNF- $\alpha$, IL- 6 and TGF- $\beta$ by inhibiting Akt/GSK3 $\beta$ signaling pathway, thus preventing the fibrosis process of keloid (M. Wang M. et al., 2019). Emodin was the main component of rhubarb, which had the same inhibitory effect, but mainly targeted PI3K/Akt pathway (C. Liu, 2015). Curcumin was a yellow organic compound purified from the rhizome of curcuma longa, which had good anti-inflammatory properties (Menon and sudheer, 2007). It inhibited the proliferation, contraction and ECM production in primary KFs (Phan et al., 2003). Fourthmore, it suppressed the formation of HS by reducing the secretion of IL-1, IL-6 and IL-8 (Jia et al., 2014), which the same as naringin (Shan et al., 2017). IL-6 level was also influenced by other natural extracts such as Ginseng (Pazyar et al., 2012), Ginsenoside Rg3 (Ma et al., 2020), Gambogenic acid (GNA) (Jun et al., 2021) and Lapadan (Matsui et al., 2011), which reduced the rates of hypertrophic scar formation.

\section{Stem Cells}

Stem cells also have important implications by secreting a large number of nutritional factors and anti-fibrosis factors for fibrosis diseases. Studies have shown that umbilical cord mesenchymal stem cells (UCMSCs) (Fong et al., 2014), adipose stem cells (ASCs) (J. Liu et al., 2018), bone marrow stem cells (BMSCs) (Fang et al., 2016), fetal dermal stem cells (FDSCs) (Jiao et al., 2017) and their corresponding conditioned media (CM) have a good inhibitory effect on scar fibroblasts.

After 5 days of co culture of ASCs with hypertrophic scar fibrolasts (HSFs), fibrosis factors such as IL-6, IL-8, FN, and TGF$\beta 1$ were significantly decreased, while the protective factors decorin $(\mathrm{DCN})$ and the ratio of matrix metalloprotinase-1 (MMP-1)/tissue inhibitor of metalloproteinase-1 (TIMP-1) were significantly increased (Deng et al., 2018). Moreover, ASCs reversed the occurrence of fibrosis and inflammation 
induced by TGF- $\beta$ (Deng et al., 2018). ASC-derived CM inhibited the secretion of IL-6, IL-8, a-SMA and proliferation and migration of KFs (J. Liu et al., 2018). In the red Duroc (RD) pig porcine model, delivery of autologous adipose derived regenerated cells (ADRC) immediately resulted in an upregulation of IL-6 at 2 weeks after injury (wound healing stage) and down-regulation at 2 months after treatment (early scar formation stage) (Foubert et al., 2017). The early inflammatory reaction was beneficial to the wound healing, and the later inflammatory reaction was inhibited which reduced the probability of HS formation. It showed better wound healing, less pigmentation and stiffness, more normal collagen tissue and lower vascular density (Foubert et al., 2017). A similar view was also confirmed in UCMSCs (Bonnardeaux and McCuaig, 2020). However, reports on UCMSCs are not consistent. Another study found that the supernatant from UCMSCs promoted fibrosis phenotype as a whole, and increased the production of inflammatory factors such as IL-6, IL- 8 and TGF- $\beta$ (Arno et al., 2014a). The inconsistency may be due to the varied sources of UCMSCs. Stem cells from different locations have different secretory groups, resulting in differential expression.

\section{Hyperbaric Oxygen}

High fibroblasts proliferation in keloids led to hypoxia condition (Jusman et al., 2019), which induced HIF-1a production (Z. Zhang et al., 2014). HIF-1a expression in fibroblasts stimulated TLR/MyD88/NF- $\kappa \mathrm{B}$ signaling pathway and promoted the expression of some inflammatory factors such as IL-6 (Y. Hao et al., 2020). According to the mechanism of hypoxia-induced inflammation, several clinical experiments confirmed that adjuvant hyperbaric oxygen treatment (HBOT) reduced the inflammatory reaction and recurrence rate by regulating the oxygen level. In Song's study (Song et al., 2018), 240 patients with keloid were recruited and randomly divided into two groups, Group $\mathrm{O}$ receiving HBOT after surgical resection and radiotherapy and Group $\mathrm{K}$ as control. After HBOT, both the infiltration of inflammatory cells and the expression of inflammatory factors such as IL-6, HIF-1 $a$, TNF- $\alpha, N F-\kappa$ B and VEGF obviously decreased. However, in another experiment (Y. Hao et al., 2020), no significant difference was observed in the expression of IL-6, IL-8, or IL-10. In this experiment, there were only 10 cases in each group, and HBOT was used before operation. Different treatment combinations may have different effects on the secretion of cytokines.

\section{Other Methods}

The production of IFN- $\gamma$ in the serum of normal patients was higher than keloid persons (Mccauley et al., 1992), which may cause keloid formation by increasing IL- 6 secretion. IFN- $\gamma$ regulated the secretion of IL-6 (Xue et al., 2000) by means of stimulating MHCII and CD40 expression (Yellin et al., 1995) and associate with JAK/STAT pathway (Euler et al., 2019). The combined use of IFN- $\gamma /$ TA is better than any single use (Mccauley et al., 1992). TSG-6 exhibited anti-inflammatory activity (R. H. Lee et al., 2009). When TSG-6 was intradermally injection into ear wounds, it resulted in lower secretion levels of IL-1 $\beta$, IL-6 and TNF- $\alpha$ (H. Wang et al., 2015). Moreover, the expression of TSG-6 protein in keloid was decreased (Tan et al., 2011). It is likely that exogenous TSG-6 may significantly diminish the development of keloid. Injection of Stromal vascular fraction (SVF)-gel or SVF cells reduced the macrophages infiltration in dermal layer, and decreased mRNA expression of IL- 6 and MCP-1, so that the level of myofibroblasts and collagen deposition were reduced (J. Wang et al., 2019). SVF gel also restored subcutaneous adipose tissue and made HS appear soft and unobvious (J. Wang J. et al., 2019). Silver containing hydraulic fiber (HFAg) and polylactic acid membrane (PLM) are two different burn dressings. Compared with the HFAg, IL-6 and TNF- $\alpha$ levels decreased in early days in both serum and tissue samples to reach normal ranges by PLM, which would prevent the development of HS (Demircan et al., 2021). Reports on UVA are contriversial for keloid. In general, UVA had a good effect on KFs, but it activated p38/NF- $\mathrm{B}$ pathway, which increased the release of IL- 6 and IL- 8 and the overall inflammatory response (Niu et al., 2020). Therefore, the simple cellular phenotype can not fully explain the controversy, and in vivo experiments are needed to verify the effect of UVA.

\section{IL-10}

The expression of IL-10 was decreased in keloid (J. H. Shi et al., 2013; Z. Chen et al., 2018) and HS (Yang et al., 2018). Intrinsic lack of IL-10 may result in continued amplification of the inflammatory cytokine cascade, continued stimulation of fibroblasts, and abnormal collagen deposition (Liechty et al., 2000). Peranteau et al. (Peranteau et al., 2008) showed that overexpression of IL-10 decreased inflammation and created an environment for wound sites in the adult to more closely resemble the profile seen in the embryo. IL-10 inhibited the secretion of IL-6 and IL-8, which induced inflammatory cascade reaction, promoted fibroblasts proliferation and collagen synthesis (Mccauley et al., 1992; Liechty et al., 2000M. Zhang et al., 2016). According to these results, the use of recombinant human (RH) IL-10 may be a potential treatment for keloid. And better results may be achieved through some new assembly methods and means.

\section{Direct Effect of Targeting IL-10}

IL-10 itself could directly inhibit the growth of KFs, but it had no effect on normal scar fibroblasts (NSFs), which was the same as Ji's report (J. Shi et al., 2014), but this was slightly different from that reported by Moroguchi (Moroguchi et al., 2004), who observed that IL-10 inhibited the proliferation of fibroblasts induced by TNF- $\alpha$ (Shi et al., 2019). This may be caused by different cell lines and concentrations of IL-10. Shi et al. (J. H. Shi et al., 2013) found that the injection of IL-10 improved the morphology of scar, inhibited the contracture of wound, narrowed the edge of wound, and relieved the deposition of collagen (col1 and col3) in regenerated tissue. Lentivirusmediated overexpression of IL-10 reduced the inflammatory response to injury after $3^{\circ}$ days, showing a favorable environment for wound healing (Peranteau et al., 2008). On 
the contrary, if the IL-10 gene was knocked out, the injury sites would present an increased inflammatory response and excessive collagen deposition (da Silva et al., 2017). IL-10 RB, a functionblocking antibody against the IL-10 receptor, blocked the IL-10mediated mitigation of fibrosis in HSFs (J. Shi et al., 2014). And it has also been verified in clinical human experiments. The experiment of Kieran et al. (Kieran et al., 2013) well illustrated that the appearance and histology of scar treated with exogenous RH IL-10 were improved. Denervated wounds could lead to abnormal wound healing and caused hypertrophic scars. In addition, when IL-10 was added to the injury model of CD1 mice, the patterns of reinnervation and revascularization were improved and the collagen tissue of the dermis was closer to the normal skin healing than the control (Henderson et al., 2011).

\section{Regulation of IL-10 Related Pathways}

After treatment with IL-10, the expression of col1 and col3 in KFs was significantly reduced, and the levels of TGF- $\beta, \operatorname{smad} 2 / 3$ and Smad4 were down-regulated, while the level of smad7 was upregulated, suggesting that IL-10 inhibited the formation of keloid by inhibiting the classic TGF- $\beta$ /Smad signal pathway of fibrosis (Shi et al., 2019). Lipopolysaccharide (LPS) could induce NFs into HFs and participate in the formation of HS by TLR4/NF- $\kappa B$ pathway (J. Shi et al., 2021), and promote the production of inflammatory molecules (J. Wang et al., 2011). The addition of IL-10 inhibited the inflammation and fibroblast filled collagen lattice (FPCL) contracture induced by LPS, which was associated with regulating the IL-10R/STAT3 axis of TLR4/NF- $\kappa$ B pathway in skin fibroblasts (J. Shi et al., 2021). In the rabbit ear hypertrophic scar model, BMSCs modified with IL-10 inhibited the expression of TNF- $\alpha$, IL- 6 and IL$1 \beta$ mRNA through JNK/NF- $\kappa$ B pathway, which significantly reduced the wound healing time, scar area and height (Xie et al., 2020). IL-10 protected HSFs from fibrosis by activating Akt and STAT3 signal transduction pathways to reduce collagen production (J. Shi et al., 2014). Moreover, skin autophagic capability is associated with HS. IL-10 also inhibited starvation-induced autophagy, which was mediated by the cross talk IL10-IL10R-STAT3 and IL10-AKTmTOR pathways (J. Shi et al., 2016) (Figure 1).

\section{A New Method of Targeting IL-10}

In order to improve the function of IL-10 and reduce the side effects, new methods have been developed which enhance the function of IL-10 through some corresponding combination and packaging means. Park et al. (Park et al., 2019) developed a new delivery platform coacervates (COA), which had features of high biocompatibility, easy preparation and better protection of growth factors including TGF- $\beta 3$ and IL-10 (Lichtman et al., 2016). Both TGF- $\beta 3$ and IL-10 had anti-fibrosis effect in physiological wound healing process. Shi et al. (J. Shi et al., 2015) designed a novel hybrid protein RHIL10-RGD, which was fused and expressed in E. coli BL21 (DE3). Treatment of HSFs with RH IL10 RGD was similar to that of RH IL10 in antifibrosis, but the former could specifically reduce angiogenesis. In addition, the Orf viru encoded vascular endothelial growth factor (VEGF)-E and interleukin-10 (ovil-10), which synergistically enhanced skin repair, and acted in a complimentary fashion to improve scar quality (Wise et al., 2020).

\section{IL-1}

IL-1, also known as lymphocyte stimulating factor, has two forms: IL- $1 \alpha$ and IL-1 $\beta$ (Gabay et al., 2010), which are mainly produced by monocyte macrophages. IL-1 played an important role in the early stage of scar formation (Jfri et al., 2019). Although impaired production of keratinocyte-derived growth factors, such as IL-1 $\alpha$, lead to a decrease in the catabolism of the dermal (Niessen et al., 2001), the role in scar formation of IL-1 $\alpha$ remains controversial. However, IL-1 $\beta$ occupied a more important position in keloid (Vinaik et al., 2020; Le et al., 2021) and HS (Krotzsch-Gomez, 1998). IL-1 $\beta$ was overexpressed in HS at post transcriptional level, and it participated in ECM remodeling with TNF- $\alpha$ to maintain fibrosis phenotype (Salgado et al., 2012). The level of IL- $1 \beta$ predicted the formation of HS (Kwan et al., 2016).

\section{Exogenous IL-1 $\beta$ Promotes Scar Formation} IL-1 $\beta$ enhanced the signal of fibrosis in the late stage of wound healing, such as increased the expression of MCP-1, while MCP-1 and IL-6 synergistically promoted inflammation (Kawarazaki et al., 2017). The addition of IL- $1 \beta$ to NFs and HSFs could lead to oxidative stress and regulate cell apoptosis, such as the increased of heat shock transcription factor-1,IL-6 and HSP-70 and the decreased of NF- $\kappa$ B, GADD45- $\alpha$, p53 and p53 binding proteins. The oxidative stress and heat stress proteins induced by IL- $1 \beta$ are important mediators of abnormal scar formation after severe burns (Barrow and Dasu, 2005) IL-1 $\beta$ also decreased the endogenous Prostaglandin E2(PEG2)secretion in KFs, which inhibited cell migration and contraction, and down regulated collagen synthesis (Sandulache et al., 2007). These factors may jointly promote scar formation.

\section{Blocking IL-1 $\beta$ Inhibits Scar Formation}

The expression and activity of chymase in keloid tissue were increased, which promoted the formation of keloid through IL-1 $\beta$, coll and TGF- $\beta 1$ (R. Wang R. et al., 2015). Blocking chymase pathway may be an effective method to improve keloid. Inflammatory body is the main regulator of inflammation and metabolic response. The activation of NLRP3 facilitated cleaved caspase-1 processing and promoting the release of IL- $1 \beta$ and IL-18, and increased the inflammatory response in keloid (Vinaik et al., 2020). Moreover, the use of NLRP3 inhibitor MCC950 reduced the expression of IL-1 $\beta$ (Ogawa, 2017; Perera et al., 2018 ), and inhibiting the activation of IL-1 $\beta$ in inflammatory body may be a method to inhibit keloid. The expression level of IL- $1 \beta$ in epidermis was directly related to the degree of skin fibrosis. In the rabbit ear hypertrophic scar model, Corrie 1 et al. (Gallant-Behm and Mustoe, 2010) confirmed that occlusion with silicone gel increased the hydration state of epidermis in a dose-dependent manner, and inhibited fibrosis and alleviated HS (Sandulache et al., 2007) by significantly reducing the epidermal expression of profibrotic cytokine IL-1 $\beta$. Tranilast inhibited fibroblasts proliferation through lower the production of IL-1 $\beta$ by macrophages and other inflammatory cells, thus lessen keloid (Suzawa et al., 1992). Beyond that,Collagen-polyvinylpyrrolidone also changed the inflammatory process of HS by reducing the expression of proinflammatory cytokines IL-1 $\beta$ and TNF- $\alpha$ (Krotzsch-Gomez, 1998). 
Interleukin-1 receptor antagonist (IL-1RA) is a member of the IL-1 gene family, which binds to IL-1R and specific blocks the activity of IL-1 (Gabay et al., 2010). In the New Zealand rabbit model, administration of IL-1RA effectively reduced skin fibrosis, and the expression of downstream signal C-FOS was blocked (Gallant-Behm et al., 2011). In addition, the expression of IL-1RA was increased in the treatment of keloid by HBOT in the clinical experiment of Hao (Y. Hao et al., 2020), which reduced the level of inflammation and played a better curative effect. Therefore, suppressing the expression of IL-1 $\beta$ attenuates scar formation.

\section{OTHER INTERLEUKINS}

\section{IL-4/IL-13}

There was evidence that the expression of interleukin-4 (IL-4) (Tredget et al., 2006; Yang et al., 2018), interleukin-13 (IL-13) (Li et al., 2015) and their receptors (Diaz et al., 2020) were increased in pathological scars. IL-13 and IL-4 up-regulated the expression of collagen related genes, inhibited the degradation of collagen induced by MMP-1 and MMP-3, and promoted collagen deposition (Oriente et al., 2000). Compared with wild-type mice, the scarring formation in T-celldeficient mice was reduced by nearly nine fold, which may be closely related to the decreased expression of T-cell-dependent Th2 cytokines (IL-4 and IL-13) and chemokines (MCP-1) (Wong et al., 2011).

Maeda et al. demonstrated that IL-4 and IL-13 induced the expression and secretion of periostin, which in turn to induce RhoA/ROCK pathway to mediate the TGF- $\beta 1$ expression (Maeda et al., 2019). TGF- $\beta 1$ was recognized as one of the important factors in keloid formation (Berman et al., 2017), which in turn acted as periostin, forming a positive feedback loop (Maeda et al., 2019). Dupilumab is a completely humanized monoclonal antibody against IL-4Ra. Unexpectedly, it had inhibitory effect on keloid associated with atopic dermatitis. Based on this, the same results were obtained in the treatment of three cases of chronic keloid without atopic dermatitis (Diaz et al., 2020).

\section{IL-17}

Interleukin-17 (IL-17) is an inflammatory factor produced by $\mathrm{CD} 4^{+} \mathrm{T}$ cells (Chang, 2019), which can promote the activation of T cells and stimulate the production of IL- 6 , IL-8, and so on, leading the inflammation. IL-17 is considered as a marker of Th17 cell subsets (Miossec and Kolls, 2012). The infiltration of Th17 cells in keloid was increased (Le et al., 2021), and IL-17 was up-regulated in keloid and HS (J. Zhang et al., 2018). IL-17 promoted the expression of a-SMA and Col1. Compared with normal skin dervied precursor cells, keloid derived precursor cells (KPCS) expressed higher IL-17R. When altered keloid niche (mainly inflammation), which was mediated by IL-6/IL-17 axis through autocrine or paracrine, and showed uncontrolled self-renewal and increased proliferation (Q. Zhang et al., 2009). Besides, IL-17 promoted the expression of stromal cell-derived factor 1 (SDF-1) and increased the recruitment of Th17 cells from the circulatory system. This positive feedback loop may lead to excessive infiltration of $\mathrm{T}$ cells and chronic inflammation of keloid. Sta-21 reduced the expression of SDF-1 in KFs by inhibiting STAT3 pathway and break the feedback loop (Le et al., 2021). Moreover, IL-17 stimulated mice showed increased fibrosis, which induced macrophage specific subtype infiltration through MCP-dependent mechanism, resulting in delayed wound healing and increased inflammation (J. Zhang et al., 2018).

\section{IL-18}

Interleukin-18 (IL-18) is a member of the IL-1 family (Yasuda et al., 2019). It has the opposite effect to scar formation in keloid and HS. IL-18 in HS tissue and fibroblasts decreased. When the RH IL-18 was injected into the HS model of rabbit ears, and the scar was improved. It was proved that IL-18 inhibited the proliferation and promoted the apoptosis of HSFs by enhancing the expression of FasL (Le et al., 2021). However, not only the expression of IL-18 in keloid tissue, but also the receptors of IL-18R $\alpha$ and IL-18R $\beta$ was increased (Felipo et al., 2012; M. Zhang et al., 2016; Vinaik et al., 2020). When KFs were exposed to IL-18, the synthesis of collagen and ECM components were increased, and the secretion of fibrinolytic cytokines (such as IL-6 and IL-8) was up-regulated (Do et al., 2012). Moreover, when keratinocytes and keloid fibroblasts (KK/KF) were cocultured, IL-18/IL-18BP was seriously unbalanced, which promoted the formation of keloid (Do et al., 2012). It suggests that IL-18 system plays an important role in the pathogenesis of keloid through epithelial mesenchymal interaction.

\section{IL-37}

Interleukin-37 (IL-37) is a relatively new member of the IL-1 family and has been described as an anti-inflammatory mediator in various inflammatory diseases (Cavalli and Dinarello, 2018). In a cross-sectional study, it was found that the level of IL-37 was negatively correlated with the severity of keloid, but had no significant correlation with age, gender, duration of lesions or family history, indicating that the decrease of plasma IL-37 level could be used as an indicator of keloid severity (Khattab and Samir, 2020). Zhao et al. (Zhao et al., 2020) confirmed the above viewpoint, and observed IL-36 expression in keloid was also decreased. Therefore, the recombinant IL-36 and IL-37 have potential as a novel therapeutic approach in pathological scar, which is warranted in the future.

\section{IL-22}

Interleukin-22 (IL-22) is a member of the IL-10 family (Dudakov et al., 2015). In fibroblasts, IL-22 signal was activated and then guided the expression of extracellular matrix genes and differentiation of myofibroblasts. Significantly increased expression of TGF- $\beta$, IL-22 and Arg-1 in keloid was found as compared to normal scar tissue (da Cunha Colombo Tiveron et al., 2018).

\section{IL-24}

Interleukin-24 (IL-24) is also a member of the IL-10 family. The mRNA level of IL-24 in KFs was significantly lower than that in normal skin. The formation of keloid may be correlated with the down-regulation of IL-24. Adenovirus-mediated IL-24 selectively inhibited the proliferation and induce apoptosis of KFs, suggesting that IL-24 has great potential in therapy of keloid (Liang et al., 2011). 


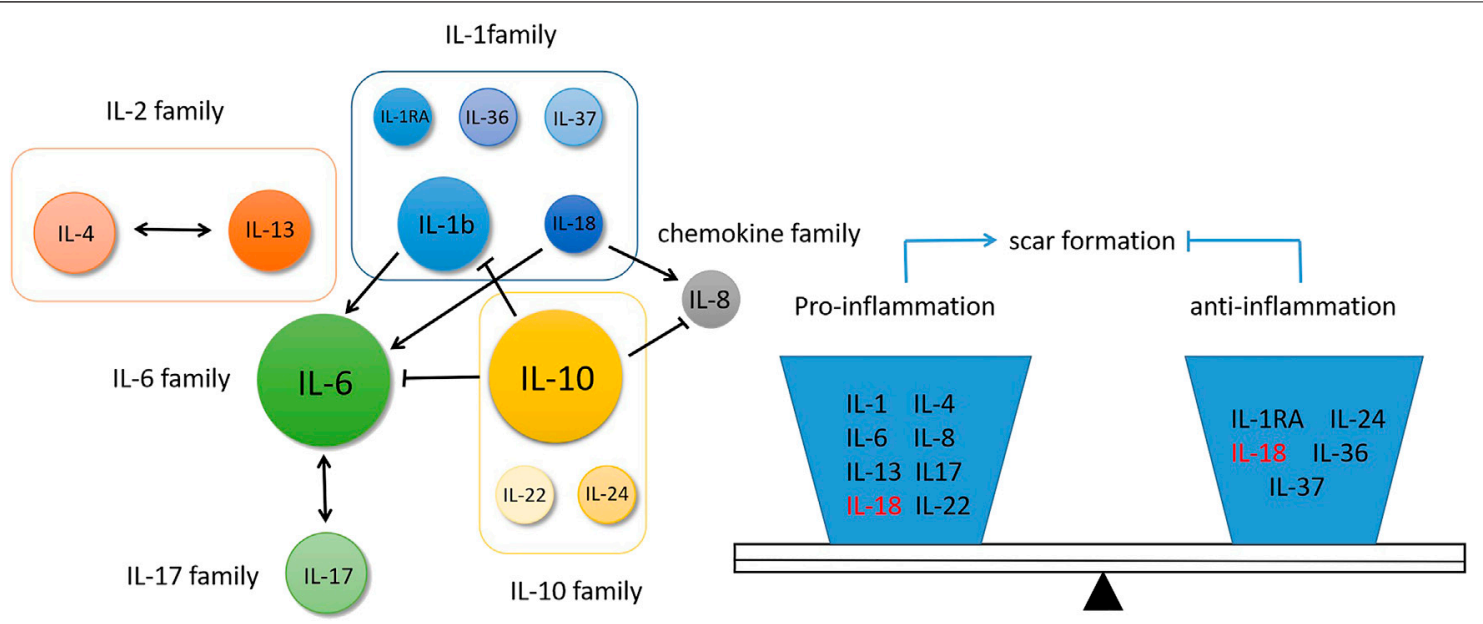

FIGURE 2 | The relationship of interleukins and their functions in scar formation.

\section{SUMMARY}

HS and keloid are both clinical challenge to be solved. The mechanism behind them has not been completely elucidated. Accumulating studies have demonstrated that HS and keloid are associated with inflammation, and thus suppression of inflammation may inhibit scar formation. Accordingly, we summarized the interleukin expression in scar and explored the influences of drugs and methods targeting interleukins.

In HS and keloid, there is a relatively large number of studies on IL-6, IL-10 and IL-1 $\beta$. As proinflammatory factors, IL- 6 and IL-1 $\beta$ play an important role in promoting scar formation. IL$1 \beta$ have been shown to stimulate IL- 6 production (Ghazizadeh et al., 2007), and they acted additively or synergistically to promote scar formation. IL-6 and IL-17 formed a positive feedback regulation (Q. Zhang et al., 2009), together with classic fibrosis factor TGF- $\beta$ in the propagation of fibrosis. On the contrary, as an anti-inflammation factor, IL-10 protected the wound healing and made it tend to scarless healing (Seifert and Mrowietz, 2009). At the same time, IL-10 inhibited the proinflammatory effect of IL-6 and IL-8 (Liechty et al., 2000) and produced antagonistic effect. Therefore, these interleukin molecules are not isolated, they crosstalk with each other to form a network regulation. During the normal wound healing and scar formation, these inflammation factors exist in equilibrium. Once the balance is broken caused by some stimulating factors, such as infection or trauma, pathological scar is generated. Currently, mote researches demonstrate the upstream or downstream signal molecules of interleukin family as indirect regulators, however it may be more intuitive that directly target certain interleukins. And this regulation has a certain intervention effect on multiple interleukin molecules (Figure 2).

Although some phenotypic and pathway effects have been observed, the crosstalk between interleukins is not fully understood. Some molecules may have two sides and differ strongly functions in varied pathways, which results in potentially contradictory outcomes. For example, in the treatment of keloid with HBOT, song (Song et al., 2018) observed that it could reduce the formation of scar by reducing inflammatory factors such as IL-6 and IL-8, while another experiment (Y. Hao et al., 2020) did not observe the same changes, but the alterations in expression of IL-12p40 and IL-RA were observed. Also, the conditioned medium from UCMCs displayed opposite effects on scar fibroblasts (Arno et al., 2014a; Bonnardeaux and McCuaig, 2020). UVA has a good effect in the overall treatment of keloid, but IL-6 and IL-8 were activated (Niu et al., 2020). The role of IL-18 in HS and keloid was conflicting, which inhibited the former and promoted the latter (Do et al., 2012; Le et al., 2021). These contradictions are worthy of further investigations in the future, and require a larger sample size and better models to validate.

Recently, researchers have also found other interleukins in scar, such as IL-22, which was activated in KFs, involved in EMC synthesis and myofibroblast transformation (da Cunha Colombo Tiveron et al., 2018). Additionally, the serum level of IL-37 was negatively correlated with the severity of keloid lesions, and IL-36, which had not been previously concerned in scars, was also mentioned (Zhao et al., 2020). It is suggested that other interleukins involved in the formation of scar may exist. And there is no intervention on these interleukins. Exogenous application of these molecules may be one of the future directions in the treatment of scar, but the concentration and safety should be paid attention to. In addition, with the development of other technologies such as tissue engineering, we may find better drug combinations and packaging methods, which will drive the development and innovation of interleukinrelated interventions.

In a word, interleukins play a significant role in HS and keloid, and targeting some interleukins and suppressing inflammation are important strategies in the treatment of pathological scar. 


\section{AUTHOR CONTRIBUTIONS}

DZ: Collection, arrangement of articles, part writing, Figs drawing; BL: Part writing; MZ: Design, part writing, modification, polishment et al.

\section{REFERENCES}

Abdou, A. G., Maraee, A. H., and Abd-Elsattar Saif, H. F. (2014). Immunohistochemical evaluation of COX-1 and COX-2 expression in keloid and hypertrophic scar. Am. J. Dermatopathol 36 (4), 311-317. doi:10. 1097/dad.0b013e3182a27b83

Abdu Allah, A. M. K., Mohammed, K. I., Farag, A. G. A., Hagag, M. M., Essam, M., and Tayel, N. R. (2019). Interleukin-6 serum level and gene polymorphism in keloid patients. Cel Mol Biol (Noisy-le-grand) 65 (5), 43. doi:10.14715/cmb/ 2019.65.5.7

Abedini, R., Sasani, P., Mahmoudi, H. R., Nasimi, M., Teymourpour, A., and Shadlou, Z. (2018). Comparison of intralesional verapamil versus intralesional corticosteroids in treatment of keloids and hypertrophic scars: a randomized controlled trial. Burns 44 (6), 1482-1488. doi:10.1016/j.burns.2018.05.005

Arno, A. I., Amini-Nik, S., Blit, P. H., Al-Shehab, M., Belo, C., Herer, E., et al. (2014a). Effect of human Wharton's jelly mesenchymal stem cell paracrine signaling on keloid fibroblasts. Stem Cell Transl Med 3 (3), 299-307. doi:10. 5966/sctm.2013-0120

Arno, A. I., Gauglitz, G. G., Barret, J. P., and Jeschke, M. G. (2014b). Up-to-date approach to manage keloids and hypertrophic scars: a useful guide. Burns 40 (7), 1255-1266. doi:10.1016/j.burns.2014.02.011

Barrow, R. E., and Dasu, M. R. K. (2005). Oxidative and heat stress gene changes in hypertrophic scar fibroblasts stimulated with interleukin-1 $\beta 1$. J. Surg. Res. 126 (1), 59-65. doi:10.1016/j.jss.2005.01.011

Berman, B., Maderal, A., and Raphael, B. (2017). Keloids and hypertrophic scars: pathophysiology, classification, and treatment. Ds 43 (Suppl. 1), S3-S18. doi:10. 1097/DSS.0000000000000819

Bonnardeaux, E., and McCuaig, C. (2020). Surgical excision combined with fully ablative carbon dioxide laser therapy and triamcinolone injections as a potential treatment for keloids in children. Pediatr. Dermatol. 37 (1), 137-141. doi:10. $1111 /$ pde.14053

Cavalli, G., and Dinarello, C. A. (2018). Suppression of inflammation and acquired immunity by IL-37. Immunol. Rev. 281 (1), 179-190. doi:10.1111/imr.12605

Chang, S. H. (2019). T helper 17 (Th17) cells and interleukin-17 (IL-17) in cancer. Arch. Pharm. Res. 42 (7), 549-559. doi:10.1007/s12272-019-01146-9

Chen, L., Wang, J., Li, S., Yu, Z., Liu, B., Song, B., et al. (2019). The clinical dynamic changes of macrophage phenotype and function in different stages of human wound healing and hypertrophic scar formation. Int. Wound J. 16 (2), 360-369. doi:10.1111/iwj.13041

Chen, Z., Zhou, L., Won, T., Gao, Z., Wu, X., and Lu, L. (2018). Characterization of CD 45 RO + memory T lymphocytes in keloid disease. Br. J. Dermatol. 178 (4), 940-950. doi:10.1111/bjd.16173

da Cunha Colombo Tiveron, L. R., da Silva, I. R., da Silva, M. V., Peixoto, A. B., Rodrigues, D. B. R., and Rodrigues, V., Jr. (2018). High in situ mRNA levels of IL-22, TFG- $\beta$, and ARG-1 in keloid scars. Immunobiology 223 (12), 812-817. doi:10.1016/j.imbio.2018.08.010

da Silva, I. R. d., Tiveron, L. C. R. d. C., da Silva, M. V., Peixoto, A. B., Carneiro, C. A. X., Reis, M. A. d., et al. (2017). In Situ cytokine expression and morphometric evaluation of total collagen and collagens type I and type III in keloid scars. Mediators Inflamm. 2017, 1. doi:10.1155/2017/6573802

Danielsen, P., Rea, S., Wood, F., Fear, M., Viola, H., Hool, L., et al. (2014). Verapamil is less effective than triamcinolone for prevention of keloid scar recurrence after excision in a randomized controlled trial. Acta Derm Venerol 96 (6), 774-778. doi:10.2340/00015555-2384

Demircan, M., Gurunluoglu, K., Gozukara Bag, H. G., Kocbiyik, A., Gul, M., Uremis, N., et al. (2020). Impaction of the polylactic membrane or hydrofiber with silver dressings on the Interleukin-6, Tumor necrosis factor- $\alpha$, Transforming growth factor-3 levels in the blood and tissues of pediatric patients with burns. Ulus Travma Acil Cerrahi Derg 27 (1), 122-131. doi:10. 14744/tjtes.2020.30483

\section{FUNDING}

Funding was provided by the Natural Science Foundation of Liaoning Province (Grant no: 2019-ZD-0929).

Deng, J., Shi, Y., Gao, Z., Zhang, W., Wu, X., Cao, W., et al. (2018). Inhibition of pathological phenotype of hypertrophic scar fibroblasts via coculture with adipose-derived stem cells. Tissue Eng. A 24 (5-6), 382-393. doi:10.1089/ten. TEA.2016.0550

Diaz, A., Tan, K., He, H., Xu, H., Cueto, I., Pavel, A. B., et al. (2020). Keloid lesions show increased IL -4/IL - 13 signaling and respond to Th2-targeting dupilumab therapy. J. Eur. Acad. Dermatol. Venereol. 34 (4), e161-e164. doi:10.1111/jdv. 16097

Do, D. V., Ong, C. T., Khoo, Y. T., Carbone, A., Lim, C. P., Wang, S., et al. (2012). Interleukin-18 system plays an important role in keloid pathogenesis via epithelial-mesenchymal interactions. Br. J. Dermatol. 166 (6), 1275-1288. doi:10.1111/j.1365-2133.2011.10721.x

Dudakov, J. A., Hanash, A. M., and van den Brink, M. R. M. (2015). Interleukin-22: immunobiology and pathology. Annu. Rev. Immunol. 33, 747-785. doi:10.1146/ annurev-immunol-032414-112123

Euler, T., Valesky, E. M., Meissner, M., Hrgovic, I., Kaufmann, R., Kippenberger, S., et al. (2019). Normal and keloid fibroblasts are differentially influenced by IFN- $\gamma$ and triamcinolone as well as by their combination. Wound Rep. Reg. 27 (5), 450-461. doi:10.1111/wrr.12722

Fang, F., Huang, R.-L., Zheng, Y., Liu, M., and Huo, R. (2016). Bone marrow derived mesenchymal stem cells inhibit the proliferative and profibrotic phenotype of hypertrophic scar fibroblasts and keloid fibroblasts through paracrine signaling. J. Dermatol. Sci. 83 (2), 95-105. doi:10.1016/j.jdermsci. 2016.03.003

Fanous, A., Bezdjian, A., Caglar, D., Mlynarek, A., Fanous, N., Lenhart, S. F., et al. (2019). Treatment of keloid scars with botulinum toxin type A versus triamcinolone in an athymic nude mouse model. Plast. Reconstr. Surg. 143 (3), 760-767. doi:10.1097/PRS.0000000000005323

Felipo, V., Urios, A., Montesinos, E., Molina, I., Garcia-Torres, M. L., Civera, M., et al. (2012). Contribution of hyperammonemia and inflammatory factors to cognitive impairment in minimal hepatic encephalopathy. Metab. Brain Dis. 27 (1), 51-58. doi:10.1007/s11011-011-9269-3

Fong, C.-Y., Biswas, A., Subramanian, A., Srinivasan, A., Choolani, M., and Bongso, A. (2014). Human keloid cell characterization and inhibition of growth with human Wharton's jelly stem cell extracts. J. Cel. Biochem. 115 (5), 826-838. doi:10.1002/jcb.24724

Foubert, P., Zafra, D., Liu, M., Rajoria, R., Gutierrez, D., Tenenhaus, M., et al. (2017). Autologous adipose-derived regenerative cell therapy modulates development of hypertrophic scarring in a red Duroc porcine model. Stem Cel Res Ther 8 (1), 261. doi:10.1186/s13287-017-0704-1

Gabay, C., Lamacchia, C., and Palmer, G. (2010). IL-1 pathways in inflammation and human diseases. Nat. Rev. Rheumatol. 6 (4), 232-241. doi:10.1038/ nrrheum.2010.4

Gallant-Behm, C. L., Du, P., Lin, S. M., Marucha, P. T., DiPietro, L. A., and Mustoe, T. A. (2011). Epithelial regulation of mesenchymal tissue behavior. J. Invest. Dermatol. 131 (4), 892-899. doi:10.1038/jid.2010.420

Gallant-Behm, C. L., and Mustoe, T. A. (2010). Occlusion regulates epidermal cytokine production and inhibits scar formation. Wound Repair Regen. 18 (2), 235-244. doi:10.1111/j.1524-475x.2010.00575.x

Ghazizadeh, M., Tosa, M., Shimizu, H., Hyakusoku, H., and Kawanami, O. (2007). Functional implications of the IL-6 signaling pathway in keloid pathogenesis J. Invest. Dermatol. 127 (1), 98-105. doi:10.1038/sj.jid.5700564

Giugliano, G., Pasquali, D., Notaro, A., Brongo, S., Nicoletti, G., D’Andrea, F., et al. (2003). Verapamil inhibits interleukin-6 and vascular endothelial growth factor production in primary cultures of keloid fibroblasts. Br. J. Plast. Surg. 56 (8), 804-809. doi:10.1016/s0007-1226(03)00384-9

Hao, R., Li, Z., Chen, X., and Ye, W. (2018). Efficacy and possible mechanisms of Botulinum Toxin type A on hypertrophic scarring. J. Cosmet. Dermatol. 17 (3), 340-346. doi:10.1111/jocd.12534

Hao, Y., Dong, X., Zhang, M., Liu, H., Zhu, L., and Wang, Y. (2020). Effects of hyperbaric oxygen therapy on the expression levels of the inflammatory factors 
interleukin-12p40, macrophage inflammatory protein- $1 \beta$, platelet-derived growth factor- $\mathrm{BB}$, and interleukin-1 receptor antagonist in keloids. Medicine (Baltimore) 99 (16), e19857. doi:10.1097/MD.0000000000019857

Haubner, F., Ohmann, E., Müller-Vogt, U., Kummer, P., Strutz, J., Gassner, H. G., et al. (2012). Effects of botulinum toxin a on cytokine synthesis in a cell culture model of cutaneous scarring. Arch. Facial Plast. Surg. 14 (2), 122-126. doi:10. 1001/archfacial.2011.734

Hedayatyanfard, K., Haddadi, N. S., Ziai, S. A., Karim, H., Niazi, F., Steckelings, U. M., et al. (2020). The renin-angiotensin system in cutaneous hypertrophic scar and keloid formation. Exp. Dermatol. 29 (9), 902-909. doi:10.1111/exd.14154

Henderson, J., Ferguson, M. W. J., and Terenghi, G. (2011). The reinnervation and revascularization of wounds is temporarily altered after treatment with interleukin 10. Wound Repair Regen. 19 (2), 268-273. doi:10.1111/j.1524475X.2011.00667.x

Jfri, A., O'Brien, E., Alavi, A., and Goldberg, S. R. (2019). Association of hidradenitis suppurativa and keloid formation: a therapeutic challenge. JAAD Case Rep. 5 (8), 675-678. doi:10.1016/j.jdcr.2019.06.001

Jia, S., Xie, P., Hong, S. J., Galiano, R., Singer, A., Clark, R. A. F., et al. (2014). Intravenous curcumin efficacy on healing and scar formation in rabbit ear wounds under nonischemic, ischemic, and ischemia-reperfusion conditions. Wound Repair Regen. 22 (6), 730-739. doi:10.1111/wrr.12231

Jiang, D., and Rinkevich, Y. (2020). Scars or regeneration? dermal fibroblasts as drivers of diverse skin wound responses. Ijms 21 (2), 617. doi:10.3390/ ijms 21020617

Jiao, Y., Wang, X., Zhang, J., Qi, Y., Gong, H., and Jiang, D. (2017). Inhibiting function of human fetal dermal mesenchymal stem cells on bioactivities of keloid fibroblasts. Stem Cel Res Ther 8 (1), 170. doi:10.1186/s13287-017-0624-0

Johnson, B. Z., Stevenson, A. W., Prêle, C. M., Fear, M. W., and Wood, F. M. (2020). The role of IL-6 in skin fibrosis and cutaneous wound healing. Biomedicines 8 (5), 101. doi:10.3390/biomedicines8050101

Jun-Zeng, Z., Huang, T. Y., Wang, Z. Z., Gong, Y. F., Liu, X. C., Zhang, X. M., et al. (2021). Scar-reducing effects of gambogenic acid on skin wounds in rabbit ears. Int. Immunopharmacol 90, 107200. doi:10.1016/j.intimp.2020. 107200

Jusman, S. W. A., Sari, D. H., Ningsih, S. S., Hardiany, N. S., and Sadikin, M. (2019). Role of hypoxia inducible factor- 1 alpha (HIF-1 $\alpha$ ) in cytoglobin expression and fibroblast proliferation of keloids. Kobe J. Med. Sci. 65 (1), E10-E18.

Kaplanski, G., Marin, V., Montero-Julian, F., Mantovani, A., and Farnarier, C. (2003). IL-6: a regulator of the transition from neutrophil to monocyte recruitment during inflammation. Trends Immunol. 24 (1), 25-29. doi:10. 1016/s1471-4906(02)00013-3

Kawarazaki, A., Horinaka, M., Yasuda, S., Numajiri, T., Nishino, K., and Sakai, T. (2017). Sulforaphane suppresses cell growth and collagen expression of keloid fibroblasts. Wound Rep. Reg. 25 (2), 224-233. doi:10.1111/wrr.12512

Khattab, F. M., and Samir, M. A. (2020). Correlation between serum IL 37 levels with keloid severity. J. Cosmet. Dermatol. 19 (9), 2428-2431. doi:10.1111/jocd. 13290

Kieran, I., Knock, A., Bush, J., So, K., Metcalfe, A., Hobson, R., et al. (2013). Interleukin-10 reduces scar formation in both animal and human cutaneous wounds: results of two preclinical and phase II randomized control studies. Wound Repair Regen. 21 (3), 428-436. doi:10.1111/wrr.12043

Kilmister, E. J., Paterson, C., Brasch, H. D., Davis, P. F., and Tan, S. T. (2019). The role of the renin-angiotensin system and vitamin $\mathrm{D}$ in keloid disorder-A review. Front. Surg. 6, 67. doi:10.3389/fsurg.2019.00067

Krötzsch-Gómez, F. E., Furuzawa-Carballeda, J., de León, L. D., Reyes-Márquez, R., and Quiróz-Hernández, E. (1998). Cytokine Expression is Downregulated by Collagen-Polyvinylpyrrolidone in Hypertrophic Scars11 The results presented in this work are part of Fernando E. Krötzsch-Gómez's doctoral dissertation. J. Invest. Dermatol. 111 (5), 828-834. doi:10.1046/j.1523-1747.1998.00329.x

Kwan, P. O., Ding, J., and Tredget, E. E. (2016). Serum decorin, interleukin- $1 \beta$, and transforming growth factor- $\beta$ predict hypertrophic scarring postburn. J. Burn Care Res. 37 (6), 356-366. doi:10.1097/BCR.0000000000000271

Le, X., and Wu, W.-W. (2021). The therapeutic effect of Interleukin-18 on hypertrophic scar through inducing Fas ligand expression. Burns 47, 430. doi:10.1016/j.burns.2020.07.008

Le, S. Y., Kim, K. E., Seo, H. B., Choi, J. W., Yoo, J. H., Jung, K. A., et al. (2021). IL17 induced stromal cell-derived factor- 1 and profibrotic factor in keloid-derived skin fibroblasts via the STAT3 pathway. Inflammation 43, 664-672. doi:10. 1007/s10753-019-01148-1

Lee, H., and Jang, Y. (2018). Recent understandings of biology, prophylaxis and treatment strategies for hypertrophic scars and keloids. Ijms 19 (3), 711. doi:10. 3390/ijms19030711

Lee, R. H., Pulin, A. A., Seo, M. J., Kota, D. J., Ylostalo, J., Larson, B. L., et al. (2009). Intravenous hMSCs improve myocardial infarction in mice because cells embolized in lung are activated to secrete the anti-inflammatory protein TSG-6. Cell Stem Cell 5 (1), 54-63. doi:10.1016/j.stem.2009.05.003

Lee, S.-S., Yosipovitch, G., Chan, Y.-H., and Goh, C.-L. (2004). Pruritus, pain, and small nerve fiber function in keloids: a controlled study. J. Am. Acad. Dermatol. 51 (6), 1002-1006. doi:10.1016/j.jaad.2004.07.054

Li, S. H., Yang, H. L., Xiao, H., Wang, Y. B., Wang, D. C., and Huo, R. (2015). Inflammation and cutaneous nervous system involvement in hypertrophic scarring. Neural Regen. Res. 10 (10), 1678-1682. doi:10.4103/1673-5374. 16776910.4103/1673-5374.162766

Liang, J., Huang, R.-L., Huang, Q., Peng, Z., Zhang, P.-H., and Wu, Z.-X. (2011). Adenovirus-mediated human interleukin 24 (MDA-7/IL-24) selectively suppresses proliferation and induces apoptosis in keloid fibroblasts. Ann. Plast. Surg. 66 (6), 660-666. doi:10.1097/SAP.0b013e3181e05039

Lichtman, M. K., Otero-Vinas, M., and Falanga, V. (2016). Transforming growth factor beta (TGF- $\beta$ ) isoforms in wound healing and fibrosis. Wound Rep. Reg. 24 (2), 215-222. doi:10.1111/wrr.12398

Liechty, K. W., Kim, H. B., Adzick, N. S., and Crombleholme, T. M. (2000). Fetal wound repair results in scar formation in interleukin-10-deficient mice in a syngeneic murine model of scarless fetal wound repair. J. Pediatr. Surg. 35 (6), 866-873. doi:10.1053/js.2000.686810.1053/jpsu.2000.6868

Liu, C. (2015). Inhibition of mechanical stress-induced hypertrophic scar inflammation by emodin. Mol. Med. Rep. 11 (6), 4087-4092. doi:10.3892/ mmr.2015.3265

Liu, J., Ren, J., Su, L., Cheng, S., Zhou, J., Ye, X., et al. (2018). Human adipose tissuederived stem cells inhibit the activity of keloid fibroblasts and fibrosis in a keloid model by paracrine signaling. Burns 44 (2), 370-385. doi:10.1016/j.burns.2017. 08.017

Ma, L., Li, L. Y., and Zhao, T. L. (2020). Anti-inflammatory effects of ginsenoside $\mathrm{Rg} 3$ on the hypertrophic scar formation via the NF- $\mathrm{\kappa B} / \mathrm{I} \kappa \mathrm{B}$ signaling pathway in rabbit ears. Pharmazie 75 (2), 102-106. doi:10.1691/ph.2020.9852

Maeda, D., Kubo, T., Kiya, K., Kawai, K., Matsuzaki, S., Kobayashi, D., et al. (2019). Periostin is induced by IL-4/IL-13 in dermal fibroblasts and promotes RhoA/ROCK pathway-mediated TGF- $\beta 1$ secretion in abnormal scar formation. J. Plast. Surg. Hand Surg. 53 (5), 288-294. doi:10.1080/2000656X.2019.1612752

Matsui, T., Ito, C., Oda, M., Itoigawa, M., Yokoo, K., Okada, T., et al. (2011). Lapachol suppresses cell proliferation and secretion of interleukin- 6 and plasminogen activator inhibitor-1 of fibroblasts derived from hypertrophic scars. J. Pharm. Pharmacol. 63 (7), 960-966. doi:10.1111/j.2042-7158.2011. 01292.x

Mccauley, R. L., Chopra, V., Li, Y.-Y., Herndon, D. N., and Robson, M. C. (1992). Altered cytokine production in black patients with keloids. J. Clin. Immunol. 12 (4), 300-308. doi:10.1007/bf00918154

Medina, J. L., Sebastian, E. A., Fourcaudot, A. B., Dorati, R., and Leung, K. P. (2019). Pirfenidone ointment modulates the burn wound bed in C57bl/6 mice by suppressing inflammatory responses. Inflammation 42 (1), 45-53. doi:10. 1007/s10753-018-0871-y

Menon, V. P., and Sudheer, A. R. (2007). Antioxidant and anti-inflammatory properties of curcumin. Adv. Exp. Med. Biol. 595 (595), 105-125. doi:10.1007/ 978-0-387-46401-5_3

Miossec, P., and Kolls, J. K. (2012). Targeting IL-17 and TH17 cells in chronic inflammation. Nat. Rev. Drug Discov. 11 (10), 763-776. doi:10.1038/nrd3794

Moroguchi, A., Ishimura, K., Okano, K., Wakabayashi, H., Maeba, T., and Maeta, H. (2004). Interleukin-10 suppresses proliferation and remodeling of extracellular matrix of cultured human skin fibroblasts. Eur. Surg. Res. 36 (1), 39-44. doi:10.1159/000075073

Mulrow, P. (1999). Angiotensin II and aldosterone regulation. Regul. Peptides 80 (1-2), 27-32. doi:10.1016/s0167-0115(99)00004-x

Murao, N., Seino, K.-i., Hayashi, T., Ikeda, M., Funayama, E., Furukawa, H., et al. (2014). Treg-enriched CD4+ T cells attenuate collagen synthesis in keloid fibroblasts. Exp. Dermatol. 23 (4), 266-271. doi:10.1111/exd.12368 
Namazi, M. R., Fallahzadeh, M. K., and Schwartz, R. A. (2011). Strategies for prevention of scars: what can we learn from fetal skin? Int. J. Dermatol. 50 (1), 85-93. doi:10.1111/j.1365-4632.2010.04678.x

Niessen, F. B., Andriessen, M. P., Schalkwijk, J., Visser, L., and Timens, W. (2001). Keratinocyte-derived growth factors play a role in the formation of hypertrophic scars. J. Pathol. 194 (2), 207-216. doi:10.1002/path.853

Niu, X., Lin, X., Chen, X., Xu, S., Huang, Z., and Tang, Q. (2020). Long-wave ultraviolet ray promotes inflammation in keloid-derived fibroblasts by activating P38-NFkappaB1 signaling pathway. J. Burn Care Res. 41 (6), 1231-1239. doi:10.1093/jbcr/iraa075

Ogawa, R. (2017). Keloid and hypertrophic scars are the result of chronic inflammation in the reticular dermis. Ijms 18 (3), 606. doi:10.3390/ ijms18030606

Oriente, A., Fedarko, N. S., Pacocha, S. E., Huang, S. K., Lichtenstein, L. M., and Essayan, D. M. (2000). Interleukin-13 modulates collagen homeostasis in human skin and keloid fibroblasts. J. Pharmacol. Exp. Ther. 292 (3), 988-994.

Park, U., Lee, M. S., Jeon, J., Lee, S., Hwang, M. P., Wang, Y., et al. (2019). Coacervate-mediated exogenous growth factor delivery for scarless skin regeneration. Acta Biomater. 90, 179-191. doi:10.1016/j.actbio.2019.03.052

Pazyar, N., Omidian, M., and Jamshydian, N. (2012). Ginseng as a potential novel addition to the antikeloid weaponry. Phytother. Res. 26 (10), a-n. doi:10.1002/ ptr.4598

Peranteau, W. H., Zhang, L., Muvarak, N., Badillo, A. T., Radu, A., Zoltick, P. W., et al. (2008). IL-10 overexpression decreases inflammatory mediators and promotes regenerative healing in an adult model of scar formation. J. Invest. Dermatol. 128 (7), 1852-1860. doi:10.1038/sj.jid.5701232

Perera, A. P., Fernando, R., Shinde, T., Gundamaraju, R., Southam, B., Sohal, S. S., et al. (2018). MCC950, a specific small molecule inhibitor of NLRP3 inflammasome attenuates colonic inflammation in spontaneous colitis mice. Sci. Rep. 8 (1), 8618. doi:10.1038/s41598-018-26775-w

Phan, T.-T., Sun, L., Bay, B.-H., Chan, S.-Y., and Lee, S.-T. (2003). Dietary compounds inhibit proliferation and contraction of keloid and hypertrophic scar-derived fibroblasts in vitro. J. Trauma Inj. Infect. Crit. Care 54 (6), 1212-1224. doi:10.1097/01.TA.0000030630.72836.32

Quong, W. L., Kozai, Y., and Ogawa, R. (2017). A case of keloids complicated by castleman's disease. Plast. Reconstr. Surg. - Glob. Open 5 (5), e1336. doi:10.1097/ GOX.0000000000001336

Ray, S., Ju, X., Sun, H., Finnerty, C. C., Herndon, D. N., and Brasier, A. R. (2013). The IL-6 trans-signaling-STAT3 pathway mediates ECM and cellular proliferation in fibroblasts from hypertrophic scar. J. Invest. Dermatol. 133 (5), 1212-1220. doi:10.1038/jid.2012.499

Salgado, R. M., Alcántara, L., Mendoza-Rodríguez, C. A., Cerbón, M., HidalgoGonzález, C., Mercadillo, P., et al. (2012). Post-burn hypertrophic scars are characterized by high levels of IL- $1 \beta$ mRNA and protein and TNF- $\alpha$ type I receptors. Burns 38 (5), 668-676. doi:10.1016/j.burns.2011.12.012

Sandulache, V. C., Parekh, A., Li-Korotky, H., Dohar, J. E., and Hebda, P. A. (2007). Prostaglandin E2 inhibition of keloid fibroblast migration, contraction, and transforming growth factor (TGF)- $\beta 1$-induced collagen synthesis. Wound Repair Regen. 15 (1), 122-133. doi:10.1111/j.1524-475X.2006.00193.x

Seifert, O., and Mrowietz, U. (2009). Keloid scarring: bench and bedside. Arch. Dermatol. Res. 301 (4), 259-272. doi:10.1007/s00403-009-0952-8

Shan, S., Zhang, Y., Wu, M., Yi, B., Wang, J., and Li, Q. (2017). Naringenin attenuates fibroblast activation and inflammatory response in a mechanical stretch-induced hypertrophic scar mouse model. Mol. Med. Rep. 16 (4), 4643-4649. doi:10.3892/mmr.2017.7209

Shi, C. K., Zhao, Y. P., Ge, P., and Huang, G. B. (2019). Therapeutic effect of interleukin-10 in keloid fibroblasts by suppression of TGF- $\beta /$ Smad pathway. Eur. Rev. Med. Pharmacol. Sci. 23 (20), 9085-9092. doi:10.26355/ eurrev_201910_19311

Shi, J.-H., Guan, H., Shi, S., Cai, W.-X., Bai, X.-Z., Hu, X.-L., et al. (2013). Protection against TGF- $\beta 1$-induced fibrosis effects of IL-10 on dermal fibroblasts and its potential therapeutics for the reduction of skin scarring. Arch. Dermatol. Res. 305 (4), 341-352. doi:10.1007/s00403-013-1314-0

Shi, J., Li, J., Guan, H., Cai, W., Bai, X., Fang, X., et al. (2014). Anti-fibrotic actions of interleukin-10 against hypertrophic scarring by activation of PI3K/AKT and STAT3 signaling pathways in scar-forming fibroblasts. PLoS One 9 (5), e98228. doi:10.1371/journal.pone.0098228
Shi, J., Shi, S., Xie, W., Zhao, M., Li, Y., Zhang, J., et al. (2021). IL-10 alleviates lipopolysaccharide-induced skin scarring via IL-10R/STAT3 axis regulating TLR4/NF-kB pathway in dermal fibroblasts. J. Cel Mol Med 25, 1554. doi:10. $1111 / \mathrm{jcmm} .16250$

Shi, J., Wan, Y., Shi, S., Zi, J., Guan, H., Zhang, Y., et al. (2015). Expression, purification, and characterization of scar tissue neovasculature endothelial celltargeted rhIL10 in Escherichia coli. Appl. Biochem. Biotechnol. 175 (1), 625-634. doi:10.1007/s12010-014-1316-1

Shi, J., Wang, H., Guan, H., Shi, S., Li, Y., Wu, X., et al. (2016). IL10 inhibits starvation-induced autophagy in hypertrophic scar fibroblasts via cross talk between the IL10-IL10R-STAT3 and IL10-AKT-mTOR pathways. Cell Death Dis 7, e2133. doi:10.1038/cddis.2016.44

Shimizu, T., Kanai, K.-I., Kyo, Y., Suzaki, H., Asano, K., and Hisamitsu, T. (2010). Effect of tranilast on matrix metalloproteinase production from neutrophils invitro. J. Pharm. Pharmacol. 58 (1), 91-99. doi:10.1211/jpp.58.1.0011

Song, K.-X., Liu, S., Zhang, M.-z., Liang, W.-z., Liu, H., Dong, X.-h., et al. (2018). Hyperbaric oxygen therapy improves the effect of keloid surgery and radiotherapy by reducing the recurrence rate. J. Zhejiang Univ. Sci. B 19 (11), 853-862. doi:10.1631/jzus.B1800132

Suzawa, H., Kikuchi, S., Ichikawa, K., and Koda, A. (1992). Inhibitory action of tranilast, an anti-allergic drug, on the release of cytokines and PGE2 from human monocytes-macrophages. Jpn. J. Pharmacol. 60 (2), 85-90. doi:10.1254/ jjp. 60.85

Tan, K., McGrouther, D., Day, A., Milner, C., and Bayat, A. (2011). Characterization of hyaluronan and TSG-6 in skin scarring: differential distribution in keloid scars, normal scars and unscarred skin. J. Eur. Acad. Dermatol. Venereol. 25 (3), 317-327. doi:10.1111/j.1468-3083.2010. 03792.x

Tosa, M., Watanabe, A., and Ghazizadeh, M. (2016). IL-6 polymorphism and susceptibility to keloid formation in a Japanese population. J. Invest. Dermatol. 136 (5), 1069-1072. doi:10.1016/j.jid.2016.01.019

Tredget, E. E., Yang, L., Delehanty, M., Shankowsky, H., and Scott, P. G. (2006). Polarized Th2 cytokine production in patients with hypertrophic scar following thermal injury. J. Interferon Cytokine Res. 26 (3), 179-189. doi:10.1089/jir.2006. 26.179

Verhiel, S., Piatkowski de Grzymala, A., and van der Hulst, R. (2015). Mechanism of action, efficacy, and adverse events of calcium antagonists in hypertrophic scars and keloids. Dermatol. Surg. 41 (12), 1343-1350. doi:10.1097/DSS. 0000000000000506

Vinaik, R., Barayan, D., Auger, C., Abdullahi, A., and Jeschke, M. G. (2020). Regulation of glycolysis and the Warburg effect in wound healing. JCI Insight 5 (17). doi:10.1172/jci.insight.138949

Wang, C., Song, X., Li, Y., Han, F., Gao, S., Wang, X., et al. (2013). Low-dose paclitaxel ameliorates pulmonary fibrosis by suppressing TGF- $\beta 1 / \mathrm{smad} 3$ pathway via miR-140 upregulation. PLoS One 8 (8), e70725. doi:10.1371/ journal.pone.0070725

Wang, H., Chen, Z., Li, X.-J., Ma, L., and Tang, Y.-L. (2015). Anti-inflammatory cytokine TSG-6 inhibits hypertrophic scar formation in a rabbit ear model. Eur. J. Pharmacol. 751, 42-49. doi:10.1016/j.ejphar.2015.01.040

Wang, J., Hori, K., Ding, J., Huang, Y., Kwan, P., Ladak, A., et al. (2011). Toll-like receptors expressed by dermal fibroblasts contribute to hypertrophic scarring. J. Cel. Physiol. 226 (5), 1265-1273. doi:10.1002/jcp.22454

Wang, J., Liao, Y., Xia, J., Wang, Z., Mo, X., Feng, J., et al. (2019). Mechanical micronization of lipoaspirates for the treatment of hypertrophic scars. Stem Cel Res Ther 10 (1), 42. doi:10.1186/s13287-019-1140-1

Wang, M., Chen, L., Huang, W., Jin, M., Wang, Q., Gao, Z., et al. (2019). Improving the anti-keloid outcomes through liposomes loading paclitaxel-cholesterol complexes. Ijn 14 1385-1400. doi:10.2147/IJN.S195375

Wang, R., Chen, J., Zhang, Z., and Cen, Y. (2015). Role of chymase in the local renin-angiotensin system in keloids: inhibition of chymase may be an effective therapeutic approach to treat keloids. Drug Des. Devel Ther. 9, 4979-4988. doi:10.2147/DDDT.S87842

Wang, W., Li, Z., Meng, Q., Zhang, P., Yan, P., Zhang, Z., et al. (2016). Chronic calcium channel inhibitor verapamil antagonizes TNFa-mediated inflammatory reaction and protects against inflammatory arthritis in mice. Inflammation 39 (5), 1624-1634. doi:10.1007/s10753016-0396-1 
Wise, L. M., Stuart, G. S., Jones, N. C., Fleming, S. B., and Mercer, A. A. (2020). Orf virus IL-10 and VEGF-E act synergistically to enhance healing of cutaneous wounds in mice. Jcm 9 (4), 1085. doi:10.3390/jcm9041085

Wong, V. W., Paterno, J., Sorkin, M., Glotzbach, J. P., Levi, K., Januszyk, M., et al. (2011). Mechanical force prolongs acute inflammation via T-cell-dependent pathways during scar formation. FASEB j. 25 (12), 4498-4510. doi:10.1096/fj.10-178087

Xie, F., Teng, L., Xu, J., Lu, J., Zhang, C., Yang, L., et al. (2020). Interleukin-10 modified bone marrow mesenchymal stem cells prevent hypertrophic scar formation by inhibiting inflammation. Pharmazie 75 (11), 571-575. doi:10. 1591/ph.2020.0572

Xue, H., McCauley, R. L., and Zhang, W. (2000). Elevated interleukin-6 expression in keloid fibroblasts. J. Surg. Res. 89 (1), 74-77. doi:10.1006/ jsre.1999.5805

Yang, J. H., Yoon, J. Y., Moon, J., Min, S., Kwon, H. H., and Suh, D. H. (2018). Expression of inflammatory and fibrogenetic markers in acne hypertrophic scar formation: focusing on role of TGF- $\beta$ and IGF-1R. Arch. Dermatol. Res. 310 (8), 665-673. doi:10.1007/s00403-018-1856-2

Yasuda, K., Nakanishi, K., and Tsutsui, H. (2019). Interleukin-18 in health and disease. Ijms 20 (3), 649. doi:10.1016/j.fsc.2015.12.00910.3390/ijms20030649

Yellin, M. J., Winikoff, S., Fortune, S. M., Baum, D., Crow, M. K., Lederman, S., et al. (1995). Ligation of CD40 on fibroblasts induces CD54 (ICAM-1) and CD106 (VCAM-1) up-regulation and IL-6 production and proliferation. J. Leukoc. Biol. 58 (2), 209-216. doi:10.1002/jlb.58.2.209

Zhang, J., Qiao, Q., Liu, M., He, T., Shi, J., Bai, X., et al. (2018). IL-17 promotes scar formation by inducing macrophage infiltration. Am. J. Pathol. 188 (7), 1693-1702. doi:10.1016/j.ajpath.2018.04.005

Zhang, M., Xu, Y., Liu, Y., Cheng, Y., Zhao, P., Liu, H., et al. (2016). ChemokineLike factor 1 (CKLF-1) is overexpressed in keloid patients. Medicine (Baltimore) 95 (11), e3082. doi:10.1097/MD.0000000000003082
Zhang, Q., Yamaza, T., Kelly, A. P., Shi, S., Wang, S., Brown, J., et al. (2009) Tumor-like stem cells derived from human keloid are governed by the inflammatory niche driven by IL-17/IL-6 axis. PLoS One 4 (11), e7798. doi:10.1371/journal.pone.0007798

Zhang, Z., Nie, F., Kang, C., Chen, B., Qin, Z., Ma, J., et al. (2014). Increased periostin expression affects the proliferation, collagen synthesis, migration and invasion of keloid fibroblasts under hypoxic conditions. Int. J. Mol. Med. 34 (1), 253-261. doi:10.3892/ijmm.2014.1760

Zhao, Y., Shi, J., and Lyu, L. (2020). Critical role and potential therapeutic efficacy of interleukin-37 in the pathogenesis of keloid scarring. J. Cosmet. Dermatol. 19 (7), 1805-1806. doi:10.1111/jocd.13357

Zhu, G., Cai, J., Zhang, J., Zhao, Y., and Xu, B. (2007). Abnormal nuclear factor (NF)- $\mathrm{BB}$ signal pathway and aspirin inhibits tumor necrosis factor $\alpha$-Induced NF- $\kappa B$ activation in keloid fibroblasts. Dermatol. Surg. 33 (6), 697-708. doi:10. $1111 /$ j.1524-4725.2007.33146.x

Zhu, X. J., Li, W. Z., Li, H., Fu, C. Q., and Liu, J. (2017). Association of interleukin-6 gene polymorphisms and circulating levels with keloid scars in a Chinese Han population. Genet. Mol. Res. 16 (2). doi:10.4238/gmr16029110

Conflict of Interest: The authors declare that the research was conducted in the absence of any commercial or financial relationships that could be construed as a potential conflict of interest.

Copyright (c) 2021 Zhang, Li and Zhao. This is an open-access article distributed under the terms of the Creative Commons Attribution License (CC BY). The use, distribution or reproduction in other forums is permitted, provided the original author(s) and the copyright owner(s) are credited and that the original publication in this journal is cited, in accordance with accepted academic practice. No use, distribution or reproduction is permitted which does not comply with these terms. 